\title{
Imagens na pesquisa com professores: o oral e a fotografia
}

\section{Images in the research into teachers: verbal and the photograph}

\author{
Valeska Maria Fortes de Oliveira* \\ Vânia Fortes de Oliveira** \\ Laura Elise de Oliveira Fabrício***
}

Resgatar a memória e recontar a história é resignificar

o olhar

Sonia Kramer

\begin{abstract}
RESUMO
A proposta deste texto é pensar o oral e a fotografia como ferramentas, mas também como dispositivos que dão voz e imagens as leituras de realidades e, mais especificamente, à investigação no território das ciências sociais. Nosso lugar de fala é o das ciências sociais, onde nosso envolvimento mais específico no campo da pesquisa é o da educação. Temos trabalhado com um projeto interinstitucional e transdisciplinar, porque sendo de lugares diferentes e desconhecidos, também, e principalmente, aprendemos muito destes e com estes. A experiência de investigação em rede é, uma das grandes aprendizagens que temos feito, na perspectiva de melhor compreensão do que estamos chamando de imaginários docentes. Nossa abordagem de investigação/formação com professores privilegia o trabalho da memória, capaz
\end{abstract}

* Doutora em Educação da Universidade Federal do Rio Grande do Sul (UFRGS). Professora Titular do Departamento de Fundamentos da Educação e do Programa de PósGraduação em Educação da Universidade Federal de Santa Maria (UFSM). Coordenadora do Grupo de Estudos e Pesquisas em Educação e Imaginário Social (Gepeis). Coordenadora da Pesquisa Laboratório de Imagens: significações da docência na formação de professores, com apoio do CNPq (Plano Sul de Pesquisa) e da FAPERGS. guiza@ terra.com.br

** Psicóloga da Universidade Regional do Noroeste do Estado do Rio Grande do Sul (Unijuí). Especialista em Psicologia Social e Bolsista de Apoio Técnico do CNPq.

*** Jornalista. Bolsista de Apoio Técnico do CNPq. 
de reconstruir imagens e processos de subjetivação, ressignificando as trajetórias de vida pessoal e profissional.

Palavras-chave: Imagens, história oral, fotografia, memórias, professores.

\begin{abstract}
The proposal of this text is to think oral and the photograph as instruments, but also as devices that give voice and images for the readings of realities and, more specifically to the inquiry in the territory of social sciences. Our place of speaks is of social sciences where, our more specific envolvement in the field of the research is of the education. We have worked with a interinstitucional project and to transdisciplinar, because being of different and unknown places, also and, mainly, we learn very of these and with these. The experience of inquiry in net is, one of the great learnings that we have fact, in the perspective of better understanding that we are calling imaginary professors. Our boarding of inquiry/formation with professors privileges the work of the memory, capable to reconstruct images and subjetivities of subjetivação, resignifying the trajectories of personal and professional life. Key-words: Imagines, oral history, fotographycs, memories, professors.
\end{abstract}

\title{
Introduzindo as ferramentas teóricas num Laboratório de Imagens
}

A utilização do método biográfico de história oral e da fotografia num Laboratório de Imagens que se propõe reunir e sistematizar imaginários de professores que atuam em diferentes níveis e espaços de ensino, não está centrada na preocupação de reconstruir fatos passados e presentes como verdades históricas, mas uma tentativa de compreender e capturar visões de mundo, sonhos, expectativas, desejos e comportamentos e identidades na perspectiva de conhecer um grupo social que trabalha anonimamente num espaço da sociedade - o espaço da docência. O trabalho com estas duas ferramentas: a oralidade e a fotografia proporcionam uma complementaridade na leitura, na escuta e na compreensão de imagens que compõem uma mesma realidade, ou melhor, realidades, pois vistas de ângulos diferentes, mas, complementares.

Nossas pesquisas têm se utilizado da história oral com duplo propósito: conhecer os imaginários, as culturas e os processos de formação do- 
cente, a partir das suas trajetórias de vida pessoal e profissional e, ainda, colocar o professor como sujeito histórico, de uma história cotidiana que não é contada, de um sujeito anônimo que trabalha com diferentes gerações, que vive momentos históricos com demandas políticas diferenciadas e para o qual não se dá a voz. A dimensão da oralidade (contar-se para o outro) aciona com dispositivos de formação e autoformação, mais ainda, com processos de produção de identidades, dando visibilidade a grupos que na abordagem da história cultural passam a ser vistos como construtores sentidos e significados sobre fatos, situações e experiências do mundo vivido.

As professoras, fazendo parte de um grupo que culturalmente não valoriza as memórias educacionais e, que vem historicamente construíndose como grupo social com um estatuto de profissão, vêm percebendo o potencial do trabalho com histórias de vida, onde um dos propósitos é, também, ajustar contas com o passado, na perspectiva de resignificar o presente.

Tratando da necessidade do nosso diálogo com o tempo, GIDDENS (2002, p. 72) diz que:

\begin{abstract}
"Tomar conta de nossas próprias vidas" envolve risco, porque significa enfrentar a diversidade de possibilidades abertas. O indivíduo deve estar preparado para fazer uma ruptura mais ou menos completa com o passado, se necessário, e deve contemplar novos cursos de ação que não podem ser guiados simplesmente por hábitos estabelecidos.
\end{abstract}

Trabalhar com as representações de professores como pessoas e como grupo social, trabalhar com as nossas representações como pesquisadores com professores, aciona com a construção de uma memória coletiva da história da própria docência, contada por aqueles que cotidianamente trabalham com a possibilidade da construção de uma memória do próprio país.

Através das histórias de vida contadas oralmente e pelo recurso da fotografia, nos aproximamos de imagens reconstruídas no presente, a partir dos significados atribuídos às trajetórias vividas. Conhecemos os processos de formação, visitamos as paisagens, os comportamentos, os tempos vividos através dos sentidos trazidos ao momento de fala. Falar de si, como uma intenção proposta por um pesquisador, de pesquisar em si, au- 
xiliado por imagens fotográficas, transporta-nos a outros tempos, a outros espaços e a outras práticas discursivas significativas, permitindo que se compreenda o deslocamento de sentidos individuais e coletivos na sociedade.

A oralidade traz a espontaneidade, a fotografia traz o detalhe, o cheiro, a cor, o som, acionados com o trabalho da memória que acaba, muitas vezes, precisando de fatos, acontecimentos, datas, até então "esquecidos". A história oral recupera a voz de quem viveu e o significado construído por quem relata, dando o direito do recorte daquilo que pensamos não ser interessante ficar escrito (porque a fala agora é transcrição) para outros leitores. A importância da transcrição como um momento da pesquisa que trabalha com o referencial da história oral, segundo PORTELLI (1996, p. 27), "transforma objetos auditivos em visuais, o que inevitavelmente implica mudanças e interpretação".

A pesquisa qualitativa, primando pela leitura, pela interpretação, pela aproximação das possíveis e diferentes configurações que um problema de investigação assume e as dimensões possíveis de enfoque quando pensamos na complexidade, rejeita abordagens redutoras e reducionistas, privilegiando aportes teórico-metodológicos que permitam investigações a partir da multireferencialidade dos fenômenos, dos fatos sociais e dos problemas a serem estudados.

A oralidade traz o trabalho da memória e, ainda, o trabalho da palavra, do que é dito e, do que é silenciado, pois o silêncio, na perspectiva que compartilhamos com ORLANDI (1993, p. 33-34), "não fala. O silêncio é. Ele significa. Ou melhor: no silêncio, o sentido é. (...) O silêncio não está disponível à visibilidade, não é diretamente observável. Ele passa pelas palavras. Não dura. Só é possível vislumbrá-lo, de modo fugaz. Ele escorre por entre a trama das falas".

O silêncio está na trama do trabalho da memória e, como aponta PORTELLI (1996, p. 68-69), "Estes procedimentos da oralidade põem em evidência o trabalho da palavra, da memória, da consciência". O trabalho desta consciência, segundo o autor, "manifesta-se na entrevista pelo fatigante trabalho da palavra".

Percebemos, através das pesquisas realizadas com professores, que a criação do espaço das entrevistas com os participantes vai sendo um processo criativamente proposto e, cada novo encontro, possibilita a instalação de um clima empático, viabilizando uma entrevista com mais detalhamentos, com um trabalho mais intenso da memória que reconstrói imagens e fala delas a partir de uma confiança na escuta do pesquisador. A 
escuta sensível é uma condição para que se estabeleça esta empatia entre pesquisador e pesquisado: uma escuta que não direciona, uma escuta que não interfere, uma escuta que se emociona e se permite ser atravessada pela fala do outro.

Para a realização da coleta de dados, nosso grupo elabora um roteiro, baseado em estudos bibliográficos referentes à metodologia. Esse momento serve tanto para o aprofundamento teórico-metodológico do grupo, como para a preparação dos pesquisadores-entrevistadores que se encarregam da coleta e do registro dos relatos.

É importante destacar que esse roteiro se destina apenas a guiar os pesquisadores, para que estes não percam o elo com as referências que norteiam a pesquisa, abarcando, dessa maneira, as categorias eleitas no projeto, tais como : o imaginário, os processos de escolha e de formação e as relações de gênero.

Os pesquisadores não estiveram limitados aos questionamentos estipulados no roteiro, pois é quase inevitável - e desejável - que, durante o relato, fluam outras questões que possam ressignificar o trabalho, permitindo que o sujeito se sinta à vontade para falar sobre muitas outras coisas significativas para ele (HORN et al., 2000, p. 32).

O trabalho meticuloso do pesquisador está, também, em traduzir todo este quebra-cabeça, montando as peças, categorizando-as e tratandoas a partir dos aportes teóricos escolhidos. Esta é uma das etapas da pesquisa, onde o qualitativo estará sendo garantido pelo trabalho criativo e consistente do pesquisador em tecer as articulações entre as fontes teóricas e as fontes empíricas, o singular, o particular com o geral, o específico e o momento histórico de onde as falas estão sendo produzidas. "A pessoa que faz a fita também é a mais capaz de garantir a precisão da transcrição"(THOMPSON, 1992, p. 292).

Observamos, conforme as questões éticas da história oral, o cuidado com a preservação das identidades das pessoas, buscamos sua autorização para o uso público das transcrições, dos depoimentos orais e das escritas autobiográficas. Os professores receberam seus relatos já transcritos para serem lidos e alterados quando julgassem necessário, selecionando o que disponibilizariam à divulgação pública e o que deveria ser restrito ao grupo 
de pesquisadores. Fica, também, a critério dos professores o uso de um pseudônimo ou não.

Este processo de criação, como bem disse Bachelard, faz parte do novo espírito científico, ou de um outro espírito científico, que coloca a criatividade como o princípio fundante da pesquisa e neste, há necessidade de articularmos a oralidade, o imagético, destacando na nossa fala a fotografia e a história oral destacadas neste trabalho, como recursos significativos à investigação de caráter qualitativo.

Sobre o uso das imagens durante o processo de entrevista, DEMARTINI (1997, p. 10) aponta para a potencialidade das fotografias como fonte de informações:

Há , parece-nos, uma “dialética” intensa entre o que ficou retido na memória do entrevistado e o que a imagem lhe permitiu relembrar. O relato oral e o que parece estar mais claro na memória de cada um dá o quadro geral, mas as imagens das fotos fazem aflorar novos elementos, surgem detalhes, nomes, fatos, há um aguçamento da própria memória.

A autora aponta para o aprofundamento do relato, tornando a realidade contada mais rica em detalhes, possibilitando ao pesquisador uma aproximação maior com a mesma. Destaca ainda que, a utilização das imagens, durante o processo de entrevista, traz algumas vantagens do tipo: reavivar a memória dos entrevistados, propiciando a aproximação da realidade e a inserção do pesquisador na mesma.

Este processo de reavivamento das lembranças, através de um trabalho mais refinado da memória é também visualizado nas nossas pesquisas com professores. No baú, nas caixinhas e nos álbuns ao serem trazidas para os trabalhos de escrita autobiográfica ou, no momento da entrevista, os participantes do projeto reconstroem imagens com mais detalhamentos e sentimentos.

DEMARTINI (1997, p. 11) aponta para o detalhamento e explicitação maiores das situações já descritas em entrevista, dizendo:

Parece-nos ainda que análise das fotos junto ao entrevistado permitiu estabelecer com o mesmo uma relação de maior intimidade, conhecer seu universo, pois o pesquisador aproximava-se mais concretamente da 
realidade relatada, começava a enxergar e vivenciar esta realidade mais diretamente através das imagens que lhe eram mostradas e comentadas.

Uma outra utilização da fotografia e da história oral, vivenciada pelos participantes da rede, através de uma oficina organizada a partir do trabalho da memória das pessoas sobre as imagens, revelou o que GIDDENS (2002, p. 28) aponta como a mediação da experiência.

Virtualmente toda a experiência humana é mediada - pela socialização e em particular pela aquisição da linguagem. A linguagem e a memória estão intrinsicamente ligadas, tanto ao nível da lembrança individual quanto ao da institucionalização da experiência coletiva.

O trabalho da memória com as fotografias, reunindo um acervo de imagens de vários momentos (tempos e espaços) dos pesquisadores envolvidos na pesquisa interinstitucional, viabilizou a experiência da história oral apurada pela imagem fotográfica. O objetivo desta oficina, como espaço de experimentação do grupo, foi dar visibilidade a um processo coletivo (a memória coletiva do grupo) os processos de identificação (construção e as mutações nas identidades) e, as singularidades destacadas pelas escolhas das imagens e o que estas faziam suscitar.

Abordando os processos de organização de materiais autobiográficos e os seus desdobramentos na trajetória do eu, GIDDENS (2002, p. 72) propõe que se pense na experiência da seguinte forma:

A pessoa anota um evento do passado na forma de um conto escrito no presente, lembrando o que aconteceu e os sentimentos envolvidos de maneira tão acurada quanto for capaz. Então a história é reescrita de maneira como o indivíduo gostaria que ela tivesse acontecido, com novos diálogos, sentimentos e resolução do episódio.

Ao mostrarem as fotos escolhidas e colocando suas memórias num trabalho de reconstrução de detalhes, percebemos tanto a preocupação em 
lembrar o que se sucedeu naquele momento, e os sentimentos provocados na situação relatada, como a possibilidade de um espaço para a criação de novos diálogos com as imagens, como aponta o autor citado acima.

O exercício para o grupo viabilizou, voltando as lembranças que cada foto suscitava na pessoa que estava a relatar o sentido da escolha e os significados construídos naquele registro, a reconstrução de uma memória coletiva, principalmente se tratando de um grupo de pesquisa com trajetórias comuns, mas construídas singularmente em momentos, em tempos e espaços diferentes. Uma aprendizagem para os que estão participando recentemente e, uma reorganização das trajetórias vividas sobre a proposição de uma produção coletiva.

A escolha da fotografia de uma colcha de retalhos, construída na disciplina Expressões lúdicas e saberes docentes, utilizada como imagem propostivia do objetivo do Seminário Integrado da Pesquisa, realizado recentemente, continha a percepção de novamente estarmos juntando os retalhos (pedaços contidos na memória individual de cada pessoa) e, da necessidade de reconstruírmos alguns tempos, alguns significados individuais, mas também coletivos, através do nosso acervo de fotografias.

A colagem das fotos escolhidas após um relato individual, partilhado com representações que vinham de todos, significou também a composição de nossas memórias como pessoas, como pesquisadores e como grupo. As nossas trajetórias eram simbolizadas na composição de um quadro de papel e, como uma obra de arte, cuidada pelos sentidos e significados reconstruídos pelo trabalho da memória através da oralidade. Nossos propósitos com esta oficina, onde nos experimentamos também pesquisadores das nossas memórias, vinham ao encontro de um exercício da abordagem sociopoética ${ }^{1}$ de investigação, a partir das nossas representações de grupo e, do grupo que criamos.

Todos estes recursos têm auxiliado nossas investigações e, o digital entra no nosso espaço de trabalho, possibilitando a sistematização e o trabalho em rede, viabilizando a outros grupos envolvidos na rede, um processo de comunicação e produção conjunta, através da pesquisa integrada. Trataremos com destaque na continuidade do texto o uso da história oral e da fotografia nos trabalhos de investigação/formação com professores.

1 Conforme a proposição feita por GAUTHIER, J., FLEURI, R. M.; GRANDO, B. S. Uma pesquisa sociopoética: o índio, o negro e o branco no imaginário de pesquisadores da área de Educação. Florianópolis: UFSC/NUP/CED, 2001. 


\section{Das falas aos sentidos: oralidade, identidade e memória na for- mação de professores}

A escolha do método biográfico de história oral se dá não por acreditarmos ser este apenas mais um método, mas como uma nova forma de investigação que possibilita dar voz aos sujeitos que, apesar de fazerem a história, são apenas contados e não possuem o direito de contá-la (POLLAK, 1989). Assim, entendemos que este é um método que centra-se no sujeito. Neste sentido, a escolha da história oral mostra-se contrário ao que os sociólogos designam como a história-batalha, ou seja, a história permeada por datas cronológicas, nomes e fatos, características das narrativas da história clássica, na qual os sujeitos-agentes pertenciam à classe dominante.

Além disso, o método biográfico de história oral vem romper com a concepção de dado empírico proposto pela filosofia positivista, a qual coloca que o mesmo possui valor em si mesmo, não sendo possível à interferência sobre o que é relatado. Contrapondo-se a esta idéia, a filosofia bachelardiana irá mostrar que o cientista, após ter participado ativamente do processo de reconstrução oral de forma empática, sentir-se-á convidado a criar técnicas que serão utilizadas na classificação, codificação e interpretação do conteúdo contido no relato oral.

A abordagem da história de vida é apropriada para a compreensão da cultura pelo "lado de dentro". Trata-se de um procedimento que permite a aproximação entre a teorização e os fatos empíricos (CAMARGO, 1984). Tal aproximação é fundamental para a validade da pesquisa social que não deve se limitar a teorizações formais nem ao empirismo puro.

Sabemos que nas comunidades em que a escrita se faz ausente, o relato oral tem importância capital, visto que este é o modo como todos os costumes e história permanece viva, através do relato dos mais velhos aos mais novos. Até mesmo nas comunidades em que hoje a escrita se faz presente existiu um período anterior a esta, onde a história oral era o instrumento que possibilitava a perpetuação da cultura local. 


\section{Entre o individual e o coletivo}

Apesar do valor atribuído à história oral, esta passa a ser questionada enquanto parte essencial do método biográfico, pois se acreditava que, no caso da história de vida, a ênfase era dada ao indivíduo e não ao social. Entretanto, o relato oral, como também a bibliografia escrita, embora contenha a história de um sujeito, apreende um determinado contexto social, ou seja, ao mesmo tempo que uma história baseia-se na vida de cada sujeito, ela encontra-se remetida ao social.

Como bem coloca RAPCHAN (2001, p. 47):

Neste sentido, esta abordagem procurará se aprofundar na narrativa segundo as perspectivas do dito, do escrito e do silenciado; no debate acerca das relações e dos critérios da definição das noções de memória e história, bem como de verdade e realidade à luz de uma preocupação com o sujeito produtor de narrativa, enquanto um sujeito produtor de significados que são construídos coletivamente.

Assim, podemos dizer que no momento em que escolhe-se um grupo específico a ser pesquisado, esse corresponde a um contexto de sociedade que deve ser cuidadosamente trabalhado através da escolha teórica, e consequentemente, através das categorias utilizadas para a análise dos dados.

Para saber sobre a diversidade dos processos socioculturais é preciso, segundo MARRE (1991) dar a palavra àqueles que os vivenciam, ouvir, para então buscar desvendar como nesta fala se ligam a experiência individualizada e os determinantes sociológicos. O método biográfico permite que se estabeleçam as ligações entre vida individual e vida social. A história de vida cria um documento na medida em que registra um relato sobre fenômenos sociais singularmente vivenciados. Através das histórias de vida, o investigador quer descobrir facetas do coletivo. "O que existe de individual e único numa pessoa é excedido, em todos os aspectos, por uma afinidade de influências que nela se cruzam (...) de ações que nela se exercem e que são inteiramente exteriores" (QUEIROZ , 1987, p. 283). 


\section{Validade e veracidade dos fatos}

É comum questionar o método biográfico de história de vida quanto a validade e veracidade enquanto documento, visto que esse encontra-se baseado em relatos de indivíduos, o que segundo alguns cientistas, devido à interferência da subjetividade do narrador poderia ser falseado.

A questão aqui é que, pelo fato de estarmos lidando com sujeitos, necessariamente se faz presente um conteúdo subjetivo, que funde-se com questões objetivas. O importante é que não se perca nenhuma das dimensões implicadas nos relatos, pois se por um lado o subjetivo pode ser um obstáculo, como acreditam alguns cientistas, por outro ela surge como dispositivo que faz com que tais sujeitos falem, no caso dos relatos orais ou escrevam, no caso dos relatos escritos.

Sabemos que neste caso "quando o indivíduo relata as suas experiências, ele não relata todos os fatos ou todos os eventos cronológicos. Pelo contrário, ele escolhe, ele faz uma seleção"(MARRE, 1991, p. 98). Assim, a descontinuidade como a subjetividade são partes integrantes da própria constituição humana, é a forma pela qual ele reconstrói a sua história. Além disso, o fato de conter questões subjetivas não significa, como já foi mencionado anteriormente, que os relatos não contenham pontos comuns, pois o que permeia cada relato é uma questão social comum entre os sujeitos, embora saibamos que o modo com o que cada um absorve as questões sociais seja singular.

Existe ainda uma distinção a ser considerada entre o oral e o escrito, devido à diferenciação existente entre discurso e narrativa, até mesmo no que diz respeito ao caráter de veracidade distinto para os dois. Entretanto, o que interessa realmente não é o objeto do relato, mas sim o modo como tal relato encontra-se encadeado com as classificações eleitas pela pesquisa e o quanto se encontra carregado de sentido (RAPCHAN, 2001).

\section{Memória e silêncio}

Outro aspecto também considerado pelo método biográfico de história oral é o silêncio, não entendido por nós como o não dito, mas sim como 
algo carregado de emoção. Como aborda POLLAK (1989, p. 13), as dificuldades e os bloqueios só raramente podem ser entendidos como "brancos da memória" ou "esquecimento", pois na verdade eles surgem como mecanismos para a manutenção da comunicação com o meio-ambiente, ou seja, existe por parte do sujeito "uma reflexão sobre a própria utilidade de falar e transmitir o seu passado".

Além disso, segundo este autor, existe um trabalho de enquadramento da memória, mais especificamente das memórias coletivas, certamente com o objetivo de manutenção da estrutura das instituições sociais. Entretanto, sabe-se que por mais que uma instituição possua uma estrutura sólida, não há fator que garanta tal solidez. Os instrumentos da história oral, por sua vez, mostram através das memórias individuais os limites do trabalho de enquadramento e, ao mesmo tempo, revelam um trabalho psicológico do indivíduo, onde emergem tensões e contradições entre a imagem oficial do passado e suas lembranças particulares.

A questão da memória da forma com é abordada nos leva a crer que o relato oral tenha a função de acionar a mesma, pois ao contrário da história oficial abordada em livros ou documentos, a história oral contada por sujeitos-agentes faz com que a memória seja acionada através de todos os sentidos, seja através do corpo, dos cheiros, dos gostos etc.

Apesar da história oral remontar aspectos individuais de cada sujeito, ao mesmo tempo uma memória coletiva é ativada, pois à medida em que cada indivíduo conta a sua história, esta mesma encontra-se envolta por um contexto sociohistórico que deve ser considerado, visto que, apesar da escolha do método justificar-se pelo enfoque no sujeito, a análise dos relatos levam em consideração, como já foi abordado anteriormente, as questões sociais presentes nos mesmos.

Assim, a história oral representa a realidade com as respectivas diferenças, explora as relações entre memória e história, coloca em evidência a construção dos atores de sua própria identidade, reconhece que as lembranças são as artes do indivíduo e redimensiona as relações entre passado e presente, ao perceber que o passado é construído segundo as necessidades do presente, chamando a atenção para os usos políticos do passado (LUCENA, 1999, p. 24). 


\section{Identidade e subjetividade}

Quando nos remetemos ao conceito de identidade, certamente estamos inseridos em um campo conceitual onde não há consenso, pelo menos no que diz respeito as teorias sociais. Se por um lado, o termo nos soa como algo fixo, determinado, por outro lado, a identidade, no sentido que pretendemos abordar, vem dizer dos modos como cada sujeito se apropria da subjetividade, dos modos de subjetivação.

O conceito de subjetividade aqui não é concebido como essência, mas entendido enquanto construção social (GUATTARI, 1996), sendo que existem dois modos através dos quais os indivíduos se apropriam da subjetividade: um desses modos diz respeito a uma relação de alienação e opressão e, neste caso, o indivíduo se submete à subjetividade da forma como a recebe, trata-se do que GUATTARI (1996) denominou como individuação; por outro lado, observamos o processo de singularização, onde se produz uma relação de expressão e criação e a partir do qual o indivíduo se apropria dos componentes da subjetividade.

Deste modo, a identidade, segundo o nosso olhar, passa não como determinação, onde o indivíduo encarna a subjetividade como ela se apresenta. Ao contrário, esta diz de uma diferença, de um traço, captado pelo indivíduo dentro de um leque apresentado pelo grupo a que pertence.

Em se tratando de pesquisa qualitativa na formação de professores, devemos sempre ter o cuidado de não simplificarmos as diversidades contidas nas experiências, enquadrá-las nas subjetividades dominantes. Além disso, como nos mostra VILLELA (2000, p. 93) a subjetividade "não é apenas uma simples questão de método ou de conteúdo", mas trata-se de algo mais radical.

ROLNIK (1997) aponta para a mudança de identidades locais fixas para identidades globalizadas flexíveis, as quais trazem a possibilidade de transformações de acordo com o contexto em que se apresentam. Segundo ela, tal situação não implica em um abandono da referência identitária, visto que as subjetividades tendem a negar o que as desestabilizam, na tentativa de organizar-se a partir de uma referência pré-estabelecida.

Pensar a identidade de tal forma significa dizer que ao mesmo tempo em que o indivíduo traz consigo traços da cultura, esse é capaz de apropriar-se da vida, ou seja, ele inventa formas de estar no mundo que não aquelas determinadas socialmente. 
Quem somos nós, assim encerrados em corpos sexuados, construídos enquanto natureza, passageiros de identidades fictícias, construídas em condutas mais ou menos ordenadas? Quem sou eu, marcada pelo feminino, representada enquanto mulher, cujas práticas não cessam de apontar para as falhas, os abismos identitários, contidos na própria dinâmica do ser? (SWAIN, 2002, p. 327).

Nossa preocupação é a de que, enquanto pesquisadores preocupados com a formação e autoformação, devemos nos voltar para as identidades flexíveis. Assim, devemos entender que ao contemplarmos a subjetividade, os modos de subjetivação, não estamos aplicando mais um método e/ou uma teoria, mas nos defrontamos com os modos de ser de cada indivíduo no interior das instituições sociais.

\section{Documento Fotográfico: o despertar da história oral e as possibi- lidades digitais}

Embora o uso da fotografia enquanto documento tenha sido motivo de discução durante muito tempo, hoje sabemos que seu uso para provar e atestar discussões, pesquisas ou simples registros do cotidiano é necessário e de grande valor, senão essencial. Aqui, além de trazermos à tona essa antiga discussão, debateremos mais profundamente as reais possibilidades advindas da imagem fotográfica enquanto documento de consulta em projetos científicos, a importância da utilização de tal material nas pesquisas qualitativas e as possibilidades advindas de processos fotográficos digitais, como forma de ressaltar a importância do uso de imagens fotográficas para consulta, análise e, inclusive, despertar a memória individual e coletiva dos indivíduos entrevistados.

A fotografia, desde sua invenção, está associada a idéia de realidade, de comprovação do real, prova de que os fatos captados e fixados no instantâneo aconteceram e da maneira como ali estão, um documento, portanto, de prova incontestável. Contudo, se sabe que uma fotografia não representa a total veracidade dos fatos e uma visão neutra da realidade, devido justamente a interferência subjetiva de quem registra os aconteci- 
mentos, a interferência do olhar do fotógrafo que mesmo se detendo na ação que se desenrola à sua frente, ou seja, o objeto a ser fotografado, a posição em que irá fotografar ou ângulo escolhido, interferirá no resultado da imagem e em seu sentido.

No entanto, o uso de imagens fotográficas como documento testemunhal em projetos de pesquisa se tornou uma necessidade indiscutível; as fotografias de família; as imagens sociais que falam das cidades e de seus espaços físicos; os costumes de épocas em que não estávamos presentes, mas que nos interessa saber; os móveis; as roupas; os tipos de moradia e as estruturas políticas, econômicas e sociais são partes da história da humanidade que, desde períodos muito remotos são registrados em forma de imagens, seja reprodução em desenho, gravura, pintura e escultura ou, mais precisamente no final do século XVIII e início do século XIX, na forma de imagens fotográficas, com a criação da fotografia.

Defender tal idéia é, antes de tudo, afirmar que na realidade não existem fotografias frias, conforme alguns pesquisadores já afirmaram, se referindo, dessa forma, a imagens fotográficas sem título, legenda ou desacompanhada de um relato oral, como diz $\operatorname{SIMSON}(1996$, p. 8):

Após fichar todo acervo fotográfico reunido notamos que devido às diferentes origens do material coletado e às próprias condições de coleta do mesmo as fotos catalogadas se dividiam em dois grandes grupos que denominamos: fotos frias - aquelas que praticamente só traziam as informações visuais do registro fotográfico; fotos quentes - aquelas para as quais conseguimos obter uma descrição da situação registrada e das condições e intenções do registro, feita pelo doador.

$\mathrm{Na}$ verdade, mesmo tendo a interferência do olhar de quem registrou algum acontecimento, as fotografias erroneamente classificadas de frias têm muito a contar e, portanto, muitas informações que não se anulam ou perdem a validade do fato registrado, devido à subjetividade do indivíduo fotógrafo; essa interferência de escolha de ângulo, distância focal ou profundidade de campo, que são termos específicos da linguagem fotográfica e que dependem da escolha do fotógrafo ou da necessidade imposta pela situação a ser registrada, não deixam de contar um fato real. 


\section{A fotografia despertando a memória}

Qual a importância real do uso da fotografia dentro de projetos de pesquisa? O que podemos obter de informações de uma fotografia que a faça valer como um documento? O que extraimos de um momento congelado no espaço e no tempo e que, concomitantemente, faz com que a memória recorde e resignifique as histórias contidas na mensagem de um instantâneo?

É certo dizer que ao olharmos uma fotografia, a memória é ativada de forma que acabamos lembrando de toda uma situação relativa ao instante em que se desenrolou o fato registrado e, consequentemente, outros fatos que não estão presentes na imagem fixada, detalhes subjetivos que enriquecem e se transformam em informações que podem interessar à pesquisa proposta.

Esses detalhes ditos subjetivos, ativados pelo olhar posto em cima de uma imagem de família, de um acontecimento social, de um espaço geográfico modificado com o passar dos anos e tantas outras situações que são registradas por fotógrafos de todos os tempos, fazem parte de relatos orais e de entrevistas normalmente utilizados como método qualitativo de coleta de dados em projetos e, dessa forma, temos nessa questão a maior prova da importância da fotografia como documento de pesquisa, análise, comprovação e comparação de fatos relevantes para os objetivos de um trabalho científico.

Muitos são os estudiosos que falam na força da fotografia enquanto objeto que ativa a memória dos sujeitos entrevistados, justificando seu uso e importância, portanto, dentro de projetos de pesquisa. Conforme DEMARTINI (1997, p. 10-11),

...é aqui que se distinguem mais as entrevistas com fotos, daquelas que não as têm; há um aprofundamento, a realidade parece tornar-se mais rica e o cotidiano da época mais evidente, permitindo ao pesquisador uma aproximação maior com a mesma. A introdução das imagens durante o processo da entrevista apresenta assim resultados em parte distintos, mas profundamente interligados: reaviva a memória dos entrevistados, torna uma realidade mais próxima e, ao mesmo tempo, "traz" o pesquisador para a realidade. A coleta de fotografias não pode assim ser encarada como tarefa que se distinguiu da própria entrevista; ao contrário, ela foi um 
elemento mesmo da própria entrevista, na medida que se recorreu às fotografias encontradas pelos professores como forma de reavivar a memória e coletar novas informações.

É importante ressaltar que uma fotografia sem legenda, títulos ou depoimento oral é um meio que produz informação e que pode ser usada enquanto dado para projetos de pesquisa, desde que, naturalmente, esteja inserido dentro do contexto e do objetivo dessa pesquisa. Porém, quando se consegue extrair de um depoente um relato que é despertado por uma imagem fotográfica e, portanto, tem-se então mais um dado informativo, há um material completo que engrandece os caminhos e os resultados de um trabalho científico, tornando-o cheio de novas informações.

Outro fator importante que se refere às fotografias enquanto dados utilizados como informação em projetos de pesquisa, é a presença de um fotógrafo, e isto se dá de duas maneiras: um profissional de fotografia pode, devido as técnicas que domina, recuperar materiais fotográficos que são necessários à pesquisa e que estejam danificados, e em segundo lugar, estando ciente dos objetivos da pesquisa, registrar todos os momentos do trabalho, sendo que esse material poderá ser anexado à própria pesquisa.

\section{As possibilidades digitais}

Com as novas tecnologias, muitas técnicas se aprimoraram e, consequentemente, a fotografia. Há, portanto, vários recursos, inclusive virtuais, que dinamizam e tornam-se novas possibilidades para aqueles que se valem da fotografia enquanto objeto de estudo, análise ou dado informativo, bem como a utilização de programas de última geração que são fundamentais em certos processos de projetos de pesquisa.

Hoje, para exemplificar as possibilidades advindas da fotografia digital, ao invés de filmes, papel fotográfico, revelações e ampliações, usa-se um disquete de pequeno porte que pode armazenar mais de cem imagens, recurso esse que simplifica os registros fotográficos. Também, com a fotografia digital, há a possibilidade de se corrigir defeitos e imperfeições no momento do registro dos fatos, com isso, consequentemente, há uma cer- 
ta economia, pois não haverá necessidade se fazer revelações e ampliações em laboratórios comerciais nem deslocar-se aos locais dos registros já realizados para refazer fotos tecnicamente danificadas. Sem falar, é claro, nos processos de arquivação, que além de seguros, não ocupam muito espaço. Claro que há também pequenos acidentes, como perda de arquivos, por isso e ainda justificando a presença de um profissional de fotografia, conjuntamente com os registros digitais, deve-se manter a fotografia convencional, como forma de garantir que haja mais documentos no caso da perda de alguma foto virtual.

Além dos processos fotográficos, não se pode esquecer ainda de programas que recriam espaços físicos e aqueles que reproduzem outras situações que podem ser utilizadas em projetos de pesquisa, facilitando e dinamizando o processo de recolhimento de dados, ou ainda, simulações que podem ser extremamente úteis às pesquisas.

Dessa forma, se valendo de imagens fotográficas recolhidas como dados informativos, processos de registros fotográficos convencionais ou ainda das possibilidades advindas dos processos digitais, a fotografia é de extrema e indispensável importância; ela deve ser considerada, portanto, uma fonte onde se pode buscar informações enriquecedoras e novas para um projeto que tem a finalidade de ser sério e completo. Com isso,

Uma vez que o "historiador é sempre prisioneiro das fontes", é imprescindível levar a cabo um trabalho rigoroso e metódico de diversificação das fontes de investigação, aos mais diversos níveis.

Trata-se de um esforço profundamente criativo, que obriga o historiador a uma recensão sistemática das fontes clássicas e a uma descoberta de materiais que induzem novas leituras das realidades de ontem e de hoje (NÓVOA, apud DEMARTINI, 1997, p. 28). 


\section{Lembrar, reviver e contar: a fotografia na memória e identidade do professor}

A fotografia, essa forma de linguagem, esse relógio de ver, possui em sua essência o poder de guardar todos os acontecimentos registrados e, consequentemente, o poder intrínseco de suscitar através do relato oral a memória daqueles que nela estão fixados, impressos, revelados ou reproduzidos, com suas identidades, seus passados, suas histórias, cores e vivências, experiências preservadas nas lembranças e trazidas à tona pelas imagens fotográficas desses momentos.

A relevância, portanto, do uso da fotografia enquanto instrumento de resgate da memória e identidade se dá, conforme FERREIRA e ORRICO (2002, p. 7-8), "devido a cultura da memória a partir da década de 1970 , como reação e reavaliação das práticas do passado, como resistência à perda de um passado mais confortável, estável, previsível..."

Especificamente dentro do projeto de pesquisa Laboratório de Imagens: significações da docência na formação de professores valer-se da imagem fotográfica torna-se essencial como forma de demonstração das identidades não fixas, as identidades flexíveis, que mudam, que absorvem novas significações do meio em que se encontram através das experiências vivenciadas nesse espaço de tempo e cristalizada pela técnica possibilitada pela fotografia.

Sendo que é a partir da linguagem que se criam as possibilidades de construção das referências que viabilizam a existência da memória e da identidade, a fotografia então, enquanto linguagem, serve de meio e forma de sustentação dessa viabilidade. Segundo FERREIRA e ORRICO (2002, p. 8-9),

A manifestação da linguagem nos diálogos do cotidiano, nos textos e nas imagens resulta na identificação como membros deste ou daquele grupo social. Em outras palavras, utilizamo-nos da língua e de outros sistemas de significação socialmente construídos para elaborar os significados, as representações que dão sentido à nossa existência.

Dessa forma, a linguagem fotográfica é usada como condição de desencadeamento daquilo que nela parece estar em silêncio, por sua condi- 
ção supostamente estática. Ou seja, as lembranças, a memória, a identidade e a vida dos indivíduos registrados no instantâneo.

\section{Considerações finais}

Após um período de quatro anos de pesquisa interinstitucional através da organização de uma rede entre pesquisadores de universidades do Rio Grande do Sul que vêm se ocupando com as temáticas do imaginário e da memória docente, de histórias de vida, de processos de formação e produção de subjetividades, concluímos a primeira fase de uma investigação com um número significativo de dados que estamos sistematizando através de um banco de imagens. Esta experiência e o Laboratório de Imagens: significações da docência na formação de professores, através do trabalho de investigação/formação desenvolvido por esta pesquisa, têm proporcionado aos grupos envolvidos na rede, aprendizagens de diversas ordens: o trabalho de pesquisa coletivo, a análise mais integrada das questões regionais e nacionais e, o trabalho específico e singular de cada grupo com o material coletado, gerando novos subprojetos e ampliando nossas temáticas de estudo.

A partir das categorias trabalhadas pelos pesquisadores envolvidos escolha profissional, processos de formação, gênero e saberes docentes constatamos que o trabalho da memória, reconstruído através das histórias de vida dos professores, imagens ${ }^{2}$ entendidas aqui como representações mentais que se explicitam através das narrativas orais, escritas e das fotografias, são materiais significativos num trabalho de investigação sobre como os professores se produziram professores.

$\mathrm{Na}$ necessidade de adentrar mais profundamente nos imaginários docentes e, conhecer como os professores vêm se produzindo como sujeitos, como atores sociais ou ainda, como integrantes de um grupo social (coletivo - profissão) e como pessoas (indivíduos) é que estamos investin-

2 Na rede constituída pela pesquisa Laboratório de imagens: significações da docência na formação de professores, temos um subprojeto coordenado pela professora Andréa Becker Narvaes, da Unijuí. Para maiores informações acerca das imagens mais comuns sobre a docência e a figura do professor, ver: NARVAES, A. B. Imagens docentes. In: RAYS, O. A. Educação: ensaios reflexivos. Santa Maria: Pallotti, 2002. 
do numa pesquisa sobre os saberes docentes na perspectiva de colaborar com a construção de uma outra cultura docente, não mais alicerçada em práticas discursivas de abnegação, de sacerdócio, de vocação e de extensão da condição maternal, de improvisação, de isolamento, de competitividade, de não reflexividade nas questões do ser e do fazer docente.

Temos conhecimento da atual situação na qual se encontram as escolas e os seus professores neste país. Os salários aviltantes, não possibilitando que os mesmos possam viver com dignidade e despreocupados com a sua sobrevivência e da sua família, inviabilizando compromissos mais efetivos e duradouros (em termos de dedicação) a uma escola. O tempo no magistério é fragmentado e vivido de uma forma dispersiva entre uma escola e outra.

É neste sentido que apontamos a pesquisa como promotora de uma nova prática discursiva sobre e com os professores. Trata-se de um tipo singular de pesquisa que tem como pressuposto dar voz aos professores enquanto pesquisadores de si (produtores de uma professoralidade).

Percebemos, cada vez mais, através dos congressos e seminários, o aumento do número de pesquisas que têm colocado o professor como sujeito de uma história da educação que se constrói cotidianamente. Este número significativo de trabalhos que vêm utilizando as histórias de vida de professores se soma a um movimento internacional que permite, inclusive, estudos comparativos com outros países, um dos propósitos desta pesquisa integrada que focaliza os saberes docentes construídos em contextos educacionais diferenciados.

O destaque dado à história oral, ou melhor, as narrativas orais e, a fotografia na nossa investigação, se deve, principalmente a utilização comum destas pela maioria dos pesquisadores participantes da rede e, ainda, por serem estas ferramentas potentes (dispositivos na expressão de Deleuze e Guatari) de formação e autoformação dos sujeitos.

Concluímos destacando uma reflexão de um dos nossos pesquisadores da rede, nosso querido Mario Osorio MARQUES (2000, p. 79), que nos deixa ${ }^{3}$ pensando: "Se é conversando que os homens se entendem, é se dizendo uns aos outros que os professores entendem o que querem e o que fazem, e que constróem, assim, seus saberes, os saberes da profissão, os saberes pedagógicos".

3 O texto que estamos nos referindo é "Professores Falantes de Si na Sala da Aula, na Escola e na Constituição da Pedagogia", publicado no livro "Imagens de Professor: significações do trabalho docente", organizado por OLIVEIRA, Valeska Fortes de. Publicado pela Editora da Unijuí. 


\section{REFERÊNCIAS}

BACHELARD, G. A filosofia do não: filosofia no novo espírito científico. Lisboa: Presença, 1987.

BOSI, E. Memória e sociedade: lembranças de velhos. 3. ed. São Paulo: Cia. das Letras, 1994.

CAMARGO, A. Os usos da história oral e da história de vida. Dados. Revista de Ciências Sociais, v. 27, n. 1, 1984.

DELEUZE, G.; GUATTARI, F. O que é filosofia? Tradução de: Bento Prado Júnior e Alberto Alonso Muñoz. Rio de Janeiro: Ed. 34, 1992.

DEMARTINI, Z. de B. F. Histórias de vida na abordagem de problemas educacionais. In: SIMSON, O. M. von (Org.). Experimentos com histórias de vida (Itália - Brasil). São Paulo: Vértice/Revista dos Tribunais, 1988.

. Resgatando imagens, colocando novas dúvidas: reflexões sobre o uso de fotos na pesquisa em História da Educação. Cadernos CERU, São Paulo, série 2, n. 8, 1997.

FERREIRA, L. M. A.; ORRICO, E. G. D. Linguagem, identidade e memória social: novas fronteiras, novas articulações. Rio de Janeiro: DP\&A, 2002.

FERREIRA, M. de M.; FERNANDES, T. M.; ALBERTI, V. (Orgs.). História oral: desafios para o século XXI. Rio de Janeiro: Fiocruz/Casa de Oswaldo Cruz/CPDOC Fundação Getúlio Vargas, 2000.

GAUTHIER, J.; FLEURI, R. M.; GRANDO, B. S. (Orgs.). Uma pesquisa sociopoética: o índio, o negro e o branco no imaginário dos pesquisadores da área de Educação. Florianópolis: UFSC/NUP/CED, 2001.

GIDDENS, A. Modernidade e identidade. Rio de Janeiro: Zahar, 2002.

GUATTARI, F.; ROLNIK, S. Cartografias do desejo. Petrópolis: Vozes, 1996.

HORN, C. C. et al. Passo a passo: caminhos percorridos pela pesquisa. In: OLIVEIRA, V. F. de. Imagens de professor: significações do trabalho docente. Ijuí: Unijuí, 2000.

. Imaginário e memória docente: um quebra-cabeças montado em rede. In: RAYS, O. A. (Org.). Educação: ensaios reflexivos. Santa Maria: Pallotti, 2002.

. Imagens orais, escritas e fotográficas: registros reconstruídos por professores.

História da Educação, Pelotas, v. 6, n. 12, set. 2002.

KRAMER, S. Alfabetização, leitura e escrita: formação de professores em curso. São Paulo: Ática, 2001.

KUREK, D.; OLIVEIRA, V. F. de. O “cuidado de si” na produção da subjetividade 
docente. In: VASCONCELOS, J. G.; MAGALHÃES JÚNIOR, A. G. Um dispostivo chamado Foucault. Fortaleza: LCR, 2002.

LUCENA, C. T. Artes de lembrar e de inventar: (re)lembranças de migrantes. São Paulo: Arte \& Ciência, 1999.

MARQUES, M. O. Professores falantes de si na sala de aula, na escola e na constituição da Pedagogia. In: OLIVEIRA, V. F. de. Imagens de professor: significações do trabalho docente. Ijuí: Unijuí, 2000.

MARRE, J. L. História de vida e método biográfico. Cadernos de Sociologia, Porto Alegre, v. 1, n. 1, abr. 1991.

RAPCHAN, A. Questões teóricas e metodológicas na história oral. In: MONTENEGRO, A. T.; FERNANDES, T. M. (Orgs.). História oral: um espaço plural. Recife: Universitária, UFPE, 2001.

NARVAES, A. B. Imagens docentes. RAYS, O. A. (Org.). Educação: ensaios reflexivos. Santa Maria: Pallotti, 2002.

OLIVEIRA, V. F. de O. Imaginário e memória docente: um quebra-cabeças montado em rede. In: RAYS, O. A. (Org.). Educação: ensaios reflexivos. Santa Maria: Pallotti, 2002.

ORLANDI, E. P. As formas do silêncio: no movimento dos sentidos. 2. ed. Campinas: Unicamp, 1993.

PEREIRA, M. V. Subjetividade e memória: algumas considerações sobre formação e autoformação. In: OLIVEIRA, V. F. de (Org.). Imagens de professor: significações do trabalho docente. Ijuí: Unijuí, 2000.

PEREIRA, L. M. L. Algumas reflexões sobre histórias de vida, biografias e autobiografias. História Oral, n. 3, 2000.

PERES, L. M. V.; OLIVEIRA, V. F. de. Imagens e imaginários: a dimensão simbólica do vivido e do pensado na formação de professoras. Cadernos de Educação, Pelotas, ano 11, n. 18, jan./jun. 2002.

POLLAK, M. Memória, esquecimento, silêncio. Estudos Históricos, São Paulo, n. 3, 1989.

PORTELLI, A. A Filosofia e os fatos: narração, interpretação e significado nas memórias e nas fontes orais. Tempo 2, Revista do Departamento de História, Rio de Janeiro, dez. 1996.

QUEIROZ, M. I. Relatos orais: do indizível ao dizível. Ciência e Cultura, v. 39, n. 3, mar. 1987.

ROLNIK, S. Toxicômanos de identidade: subjetividade em tempos de globalização. In: LINS, D. (Org.). Cultura e subjetividade: saberes nômades. Campinas: Papirus, 1997. 
SIMSON, O. von. A arte de recriar o passado: a metodologia da História Oral e suas possibilidades para contribuir na promoção do envelhecimento bem-sucedido. Mimeog.

SWAIN, T. N. Identidade nômade: herotopias de mim. In: RAGO, M.; ORLANDI, E.; VEIGA-NETO, A. (Org.). Imagens de Foucault e Deleuze: ressonâncias nietzchianas. Rio de Janeiro: DP\&A, 2002.

THOMPSON, P. A voz do passado - História Oral. Rio de Janeiro: Paz e Terra, 1992.

Texto recebido em 25 maio 2003

Texto aprovado em 05 set. 2003 